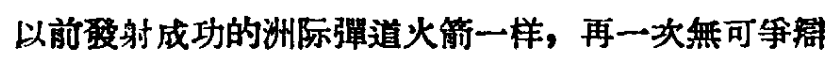
地表明了苏联科学技术的先进性，表明了以苏联为中 心的和平力量的强大。由于苏联这一偉大的成砸，在 人类文化史中一个新的时代降临了。科学家倗說：这 是人类开始从地球生物变为宇宙生物的时代，是人类 开始征服星际空閒的时代。我們中国人民和苏联人民 以及全世界爱好和平的人民一道，欢呼这个新时代的 来临。

我鹏十分高兴地看到: 苏联的坚定不移的和伻政 策正在忩来愈广泛地团結着世界上一切爱好和平的国 家和人民。苏联在原子武器、昰武器和洲际导彈等制 造方面尽管站在世界最前列，然而始終主張禁止这种 武器的使用，抹主張普遍裁軍，甚至可以裁到仅留下 民警的地步。

自从去年十月間苏联政府發了关于發謷和进一 步加强苏联同其他社会主义国家的友誼和合作的基础 的宣言以来, 通过領导人之間的一系列的訪問和会談， 已玈更进一步加品了各社会主义兄弟国 家之閵的团 結。茄联和印度、緬甸、印度尼西亚、錫兰、東埔寨、 埃及、叙利亚等亚非国家間的友好关系也正在日益弡 展和加强。我們还注意到，荻联在制止帝国主义对埃
及和叙利亚的侵略中已經起了而且正在起着巨大的作 用。苏联为了促进世界和平、緩和国际紧昆河势所作 的每一項努力，我們六亿中国人民是全力支持的，军 世界爱好和平的人民也愈来愈广泛地装示着热烈的拥 护。我們認为帝国主义好战分子們在今天是应該徹底 清醒起来，对苏联的各項和平建議認椇加以考虑扞加 以接受的时候了。

苏联的今天就是我侕的明天。苏联的光耀成就給

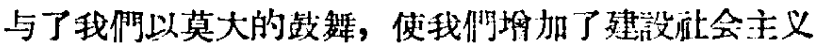
的信心和力量。我們一定要向苏联人民看齐，在中国

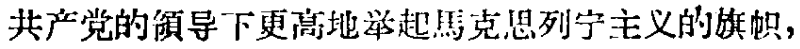
坚决地走於会主义的道路, 来促进祖国的建設事業。

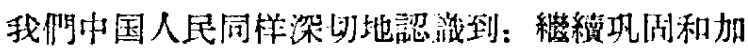
强我們与苏联人民之闍的团結和友院，是我們最高的

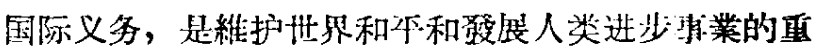
要保部。我們也一定要像保护目已的眼珠一样保护我

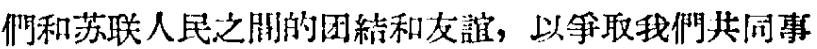
業的徽底胜利!

偉大的十月社会主义革命万岁!

战無不胜的馬克思列宁主义万岁!

世界和平万岁!

\title{
偉大十月社会主义命革的光輝 照耀着科学弡展的道路
}

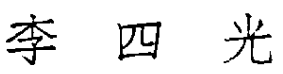

（中國科学院副院長 中策全國自然科学基門学会联合会注席）

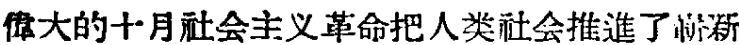

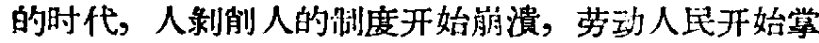
握自己的命运，創造自己的幸部前途。全世界人类的 生㴻，無論在政治、經济、科学、藝術……任何方面，

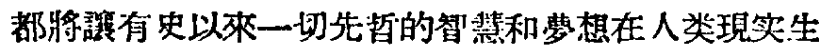
活中發揚光大，放出異彩。

十月革命是全人类万古傳誦的偉大詩篇，十月革 命是全出界人民保衛和平創造白己幸福前途的灯塔。

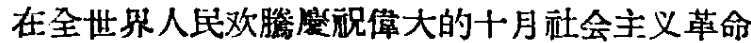
四十閔年的时候，全中國人民和科学工作者都在炊呼 十月社会主义革命的光耀勝利，欢呼以苏联为肖的社

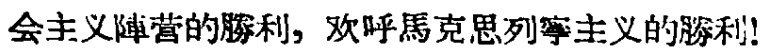

十月月革命以來的四十年中，全世第一个社会主 义國家苏联在社会声义建設的各个战践上都得了构 其偉大的勝利，尤其在發展科学事莱墳谁人类幸福方 面作出了划时代的貢献。苏联一系列的科学技術最积

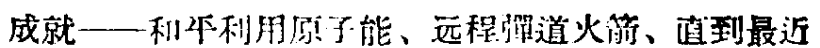
發射成沙的人造地球衛星，使全比界劳动人民为之欢

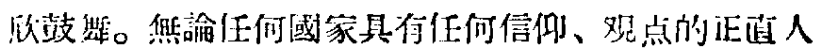

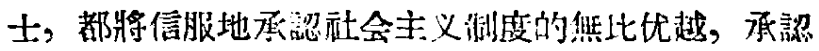
苏联科学技衔已經远远地未在全比界的最前面。

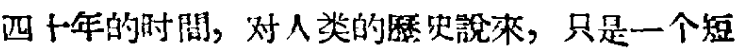
短的原程，然而苏联人民和科学技術工作者在这短短 的四十年非，却作出了如此巨大的成就。在这里应当

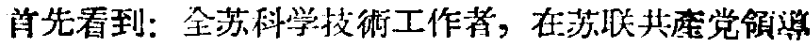
一下，在㫦大的革命等师列密同志的教算下，国敉和全 國人牫一起度过了一段艰难歲月。这一段艰苦奋斗淮

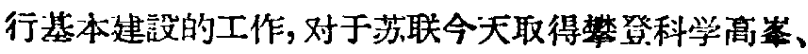
开辟人垁科学文化䉼时代的光荣，具有称为重要的意 义。在这里，我們全中國科学技術工作者，首先要对 苏联科学家、工程师們四十年來辛勤劳动的功精，表 示农心的敬港! 
中國科学技術工作者，八年來在老加我們祖國各 项絓济、文化建設的事業中，对十月革命的意义和影 响，对苏联科学技術工作的卓越成就和先進絽驗，有

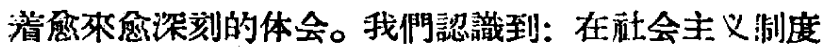
一下以馬克思列穿主义为指尊思想的科学事業，佳着凅

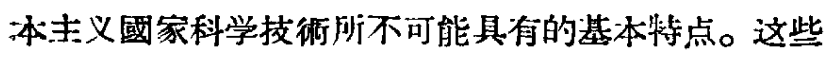
基本特点是: 科学發展的全面性、計划性和 集体 刢 造。苏联四十年來在科学技術方面的怒力，充分地發 掩了这三个基本特点，給我們从事社会主义科学事咩 的人們創造了光辉的典范。苏联科学技術的一系列成 就份力地指明: 让是这些特点决定了社会主义例度下 的科学事業不可限量的远大前途。

保大的十月社会主义革命照亮了劳动人民徹底解 放自己的道路，照亮了劳动人民發展科学事等的道

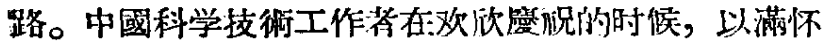
热情体驗到苏联四十年來科学技術發展中給予我們的 几点重要智示:

一、社会主义科学事業必須建立全面發展然懈可 福的战絈，为了达到这一姦求，肖先要下楛工夫，在各 个科学技街部吅進行切实認真打好基礎的艰苦奋斗。

苏联今天的科学事菜是建筑在各个科学技術部門 全面發展的坚实基礎之上的，它是一个無唃可击的科 学战螕。几年來, 苏联在科学技術上一系列的突出成 就，便是这一全面發展的科学战綫的战果。但是这一 战緎的形成，正解前面已經提到的那样，是經过一个 相当时期“卧新尝胆”艰苦努力的。在苏联進行建設工 作的初期，从一般情况看来，不象是十分注重个别部

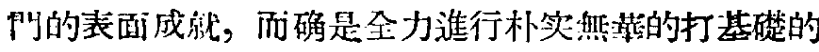
工作。这一时期对于培养新生力量、此大科学榢伍、

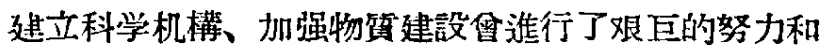
大量的組織工作，这些工作的成就，不像在某些科学 部阿或个别科学家的葉些專題研究成果那样，易于为 人們所認識。但正是这种除旧布新的工作，把各間学 科安放在馬克思列宗主义思想指導之下，从而为各門 学科打下了廣泛而坚实的基礎，才保証了苏联科学技 術今天的迅速發展, 一鳴警人。

中國科学技術各个部門，几年來正在党的領藥下 閴污地進行組織工作，有計划地建立和調整了許多研 究机構，大量地境养訓練科学干部，完成了十二年科 学枝術發展远景規划，全國科联几十一个専門学会的学 術活动也得到党和政府的大力支持。这一切努力， 玵 是我們为了科学技街全面發展所必需的打基礎的工 作。否定这种打基礎工作的意义，一味强調發表論文， 为局部工作、个人工作打小算盤，是完全錯誤的。右

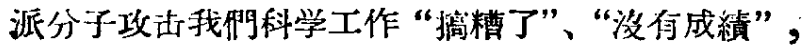
让是利用了这种盗堂階級覌点破坏我們社会主义科学

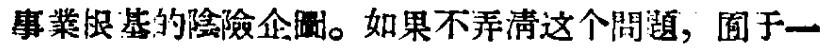

时的局部与个人的儤失；便不能 $\mathrm{IE}$ 确理解当前我圆各 个科学技衔部䍀所行行的工作的長远意义，便不可能

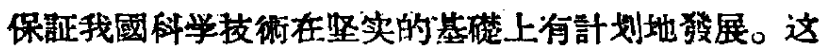

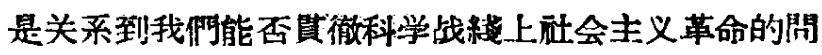
題，是我們科学界必須锌明的大是大非。我們今天必 須認学替苏联發展科学技術的症史經驗, 以埋头苦 干的精帊，完成打基礎的糜农任务。

二、科学与生隺实际相結合，是新中國科学事㩍 的根本特点; 發展科学玻淪研究与提高工農業生厫技 街必須是緊復結合、統一發展。

苏联科学事紫四十年來的發展, 充分說朋了科学 与技術的不可分离性。在資本声义制度下，科学理論 与技術創造，在荣些人們的心目中，往往不是同等直 規的。在他們看來,技術是次一科学的。例如“人造畋

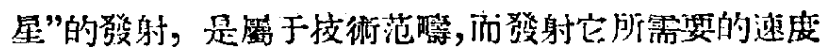

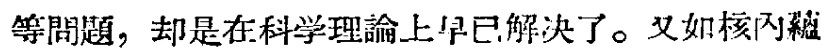
藏的能大能量，也是早已知道的事实。至于如们磁

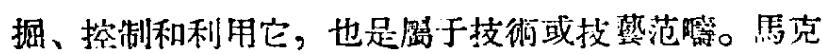
思主义者認为这种覌点是完全錯誤的。苏联科学事莱 發展的事实，也証明这种看法是完全錯誤的。

从古石器时代开始；直到今天，人类文化、科学 的發展綮史都疑示着: 每一个新的工具的刢造，常常 是促使人类文化獲得躍進的重要因素。就近代科学來 說，每一个新工具的發朋（如颖微鏡、电子斯微鏡、 光䛶仪、电子管、買譜仪等等)，都一次义一次为科学 研究工作开辟着新的領域。有重要成就的科学家，他

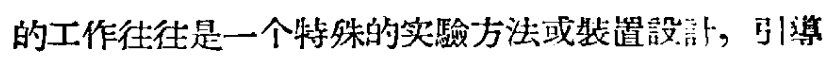
他獲得了新的成果。例如藉名的巴浦洛夫学镜的建 立，巴氏的实驗方法篔起着重要作用。

馬克思列蜜声义所教望我們“理論与实践相結合” 的原則，是我們發展㪴会主义科学事学的基本指篹思 想。这应当是我們学皙苏联先淮經驗中的另一个重罢 的体会。

三、证确处理个人与集体的关系，認潰㳊行思想 改造，接受党和政府对科学事栄的領掊，在各項科学 技衔工作中坚决貫微集体主义的精称，才能充分地歌 挥个人作用。

苏联人民在十月革命以來的四十年中，以他們一 切为了社会主义的英雄气概硘造丁一个拉新的时代。 工人階級帶領着全体劳动人民和革命知識分子以增進 全人类㩼楅与智慧为已任。”在这个新的时代，苏联科 学技街工作者已經形成了新型的工人階极知識分子的 坚强陵伍。他們问全世界提供了一个重要經驗一以 集体主义的思想進行科学工作，它的效能是㱸本主义 制度下以个人为中心的科学工作所紨对艠可比坝的。

許多事实証明了这个經驗的正确。中國儿华來的 建設工作，取得了詻多成就，一就是由于我們是在党和 
欧府的正确領導下，以展大劳动人民和全国科学技行 工作者的集体努力完成的。在整个建設过程中，我們 每时無刻不感到苏联人民和科学技街工作者的深厚友 誼，我們更無时無刻不感到苏联科学技术专家們崇高 的國际主义精帕和令人-1·分感动的裁热的爱國心。在

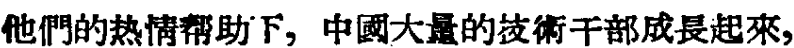
许多的重要企業完成和超積完成了第一个王年計划; 墢現了大量的自然瓷源，制定了新的数学計划，引用 了先进的医疗方法和衛生措施。苏联帮助我國建立第 一个反应堆和第一部迴旋加速器即将完成, 为原子能 工業、同位素应用和有关核物理学各方面的研究打下 基础。三阿峽水利便紐的設計，是列察格勒設計院一 千多位工程沛共同协助的成果; 获跨長江天整的武漠 大桥，也正是在苏联專家帮助下的廣大科学挍術工作 者，以及包括全國吘多生裳部門的职工集体創造的丰 功偉蹟。

但是，这条經驗，在我們思想上並不是都能够輕 易接受的。餈本主义文化教育給我們留下來的犁慣 是: 自高自大、目空一切、自由散漫、崇份个人競爭、 吗視别人的工作、反对組織的領導。这一切是恰恰和 集体主义精神不相容的。我們染染体会，这一切瓷宸 階級个人主义的思想替慣，对科学事栄的發展亚端有 害。如呆不克服这些东西，任何个人不論有多大的本 領，他的力量也还是不能發捛出來。

周然，在十月革命腾利以前俄國也有过一些傑出 的科学家，如阴捷列夫、列別唗夫、沙皇时代的巴浦洛 夫等世界閆名的学者。他們的不朽的貢献, 永远受到全 世界科学工作者的縏敬。但我們大家都承認，这样的 人果竟是少数,亚且在当时,他們的工作並朱得到，也 不可能得到有系統的發展。巴甫洛夫在沙皇时代的遭 遇和十·月革命以后受到苏联共虑党和列察同志高度的 关怀, 正是給我們科学工作者上了最为生动的一課。

要去掉资本主义唒会給予我們的不良影响，樹立 㕵会主义科学事箖所需罗的集体主义精神，主要的关 鰎在于接受共座党的領棌和敉有，坚决進行思想改造。 共党党是工人階級运动与馬克思主义相結合的奥物， 它是最先淮的集体一工人階級的先鋒跭。只有工人 階級的品等于能战腙个人主义对我椚的影响。

在中國，近代科学發展的原史是很短的，同时由 于当时牛封建牛淔民地的条件的束䌕，因而基礎也是 異常薄弱的。当然，不可否認，也有許多人作了辛勤 的工作，也有一些人有了不可醁滅的貢献。他們的工

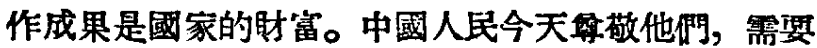
他們。但我們要知道: 过去的这些成就，对新中國來

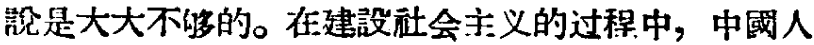
民所需要的不是少数的几个人才，而是一个巨大的科 学榢伍。这个榢伍中一个人的任务，也和过去离基
察居的时代大不相同。我們不再是只恣个人才智作工 作，而是以为社会主义集体事業而战斗的姿态接受人 民給予我們的任务。

在这里，一个更为㭚本的問題是：整个社会的知 济基礎已經改变，旧的基礎已經不倞在了。在解放前 的旧中國，帝國主义、封建階級、和官你瓷育階級从 來就不打算讓中國科学事栄得到些微登展。在那种情 况下，固然，依靠着頽垤敗壁的角涴里偶然仔在的有 利条件，或者在供亚少数悠閒者玩賞的永栽中，有时 也可能出現几朵夺目的鲜花。对于这些，人民地是一 向爱护的，但是在今天这个新时代，必需把它們移惟

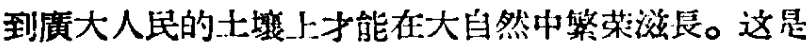
一个重大的轉变过秙。有决心完成这个轉变的，就必 然会受到人民的喜爱，得到更大的發展，在新的环境 一下生新的奇花筫种。如果不能適应新的环境需要， 改变旧的气留，那么郎使人民的土醇給予再多的营 养，也仍然只有枯萎下去。如何改造自己以獲得䡯变

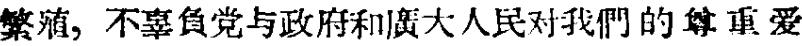
护，这是接在我們科学工作者面解需装我們染思的一 个譬重問題。

四、在黑克思列察主义思想指望下的苏联科学事 策，必然还姴不断出現無止境的高涺。

苏維埃科学在展义的物理科学（包括一切不以生 命形态为攻研对像的各門科学) 方面，已經作出了优 異的成績，肯定地走到了世界科学的最前列。

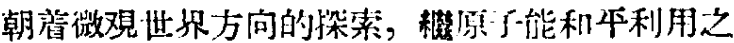
后，苏联对核于物理正在進行更偉大的工作。括托你

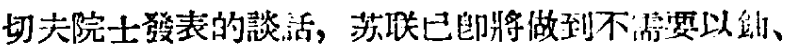

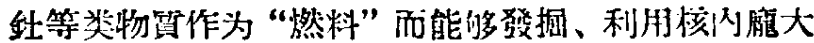
能量; 这將攵是一次警人的科学技街事策的發展。面臨 着这样的形势，世界上俏一小摄揮舞着氞武器和热核 武器, 想借以詐訛嚇人谋利的狂人, 該当情醒一些吧!

朝着䆖覌世界方向的探荣，苏联已經成功地放射 出了第一颗人造地球得是，看來还將成功地放射可以 回到地球的衛星和载人的衛星。苏联科学工作者这一 系列的冬力，使人夹跨谁宏覌宇宙空间進一步進行宏 覌世界的研究，已經由理想成为現实，开辟了甘界科 学新的紀元。

同时,在是一方面我們还应該看到: 在生物科学的 各个領域，塥会主义科学事策，还正是方兴来艾，萂藏 着無限丰富的可能性。这是資本主义國家烃本無法競 裹的。对于前一方面的研究, 資本主义舦度的洛后性固 然使他們的工作不能得到像苏咲那样的發展速度，但 某些技術成果，迟早还有实現的可能。可是在生物科 学的某些方面，特别在人的生命意識的科学方泊，资 本主义國家到了十九世世紀末叶已經走淮了死胡同，它

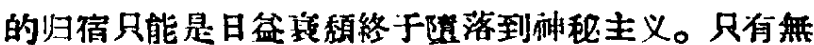




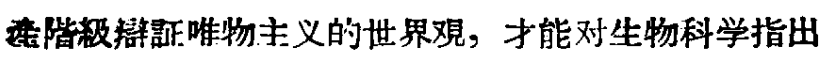
正确道路。我們相信在这方面社会主义科学事業必然 將有無限深远的㓣造前途，馬克思主义哲学也將由于 这方面的和广义的物理科学方面的工作扭鴐齐駘，獲
得更加丰富的磁痕。

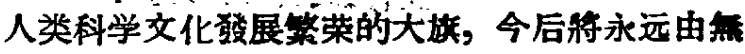

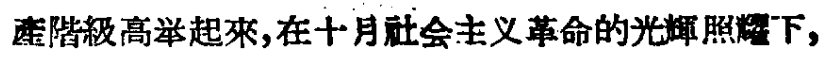
满怀信心地大步前進!

\section{学㛭苏联先進經驗 努力赶上世界水平}

\section{張 勁 夫}

(中國科学院副院展)

当我們大家正在热烈㦄呮荕联十月革命四十週年 紀念这一龦大節日的时候，我們同时让逢着苏联科学 上的大節日，这就是苏联在十月四日發射出了人类歴 史上第一顆人造地球衛星。全世界的科学工作者都在 热烈談論这件票，实际上豈但科学傢們在談論，政治 家、軍事家們以及关心人类前途的普通人們也在热烈 談論着。

現在差不多凡是睜着淑腈看事实的人，㲅不得不 承就, 这是一件偉大創䋃, 是具有原史意义的科学事 件，它标誌着科学成就的一个新紀元。当然也有不願 或不敢睜着眼睛看事实的人，例如美國海察作战参謀 银貝奈特，竟瞎說这 “只不过是一塄铁，几乎任何人

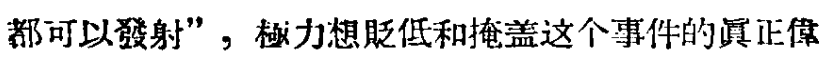
大噫义。可是这证合乎中國的一句古活：丳实滕于雄

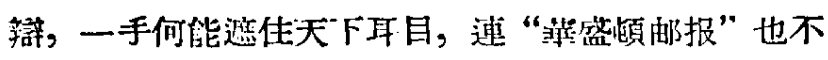
得不在社諭中吃着苦樂似地承認: “从一开头, “衛 星” 就是一个偉大的科学成就。这里任何想要低估或 忽悓它的趋势，只会使这个成就更加突出。”世界上 誠实和证直的科学家，無不在为这件創举贊美称鹿， 关心人类進步事業和爱好和吃的人們，都在为此欢 呼; 至于“一小撮死守熋断資本利谷的人，过去想用所

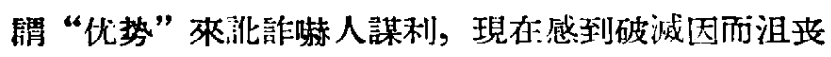
以至惶恐，这义有忆么办法呢?

这几年來，苏联在科学技街方通已有許多光耀成 就震动了世界。例如，苏联科学家首先在工業中利用 原子能，于 1954 年建立了世界第一个原子能發电站。 䓜泱第一艘裝有原子能發动机的破冰船將在今年队下 水,这艘破冰船能够航行兩三年而不必入港添加然料。 获联已經建成一百億电子伏特的粒子加速器，正在設 計五百境电子伏特的粒子加速器。苏联 “㨽-104”噴 气客机到过各國，被認为是世界上最好的噴气飛机。 至于最近發射成功的人造地球衛星，則是許多光輝成 就中更为突出的成就，因为“徨星”的發射成功，正如 托布切夫院士在談話中指出: 不是某一閏科学的勝 利，而是物理学、化学、数学、喷气技街、無緎电技 街和点他部門科学技術的勝利。
我們國內有些右派分子有时却別有用心地惡毒地 誹謗苏联，散布对茫联的不㴖情緒。科学界的右派分 子在進行这种誹謗时，常常是用誇耀美國的科学技術 先進，䏠低苏联的科学技街水平的手法，來企圖引起 人們对苏联的䡉梘和疏远，甚至挑㢸对苏联的不㴖。 有些中了“美國月亮好”的毒的人，对右派分子这种筐 曲誹謗, 有时也缺少防疫力,多少也受到一些傅深。現 在看看事实究竟怎皏呢? 过去的事实和最近的事灾,

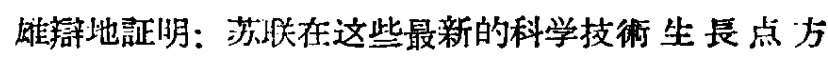
佰，是稳居世界第一位和走在科学最發达的瓷本主义

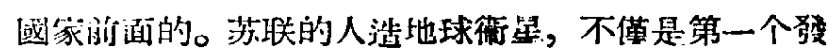
射成功，而且大家公認比美國老早就大疑宣傅而却义 迟迟發不出去的人造衛星妿优越得多。赫鲁墝夫同誌 在和賴斯頓談話中說: “如果美國今天还沟有火箭的 話, 那允將來你們也会有的, 因为科学在不断發展源。 对苏联來說也是一样: 如果你們有的什么东西积們今 天还沟有，那么我們將來会有的。”我們說茄联科学 技術走在資本主义國家的前面，並不是铞不－切方湎 都䂏过資本主义國家，美國在某些科学拔衙方通水本 是高的，我們社会主义陣营國家要努力趐上; 但从上 迅最新的科学技術生長点的成就來看, 荕联是稳步地 走在美國前面了。苏联之.所以能發射人造衛攵, 是因

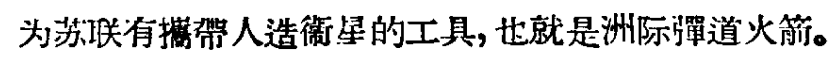
美國为什么現在还不能發射人造衙㚅呢? 也就是因为 美國没有洲际彈道火箭，如果有的話，也是可以䡒而 易举地放出人造衙星的。对于正曲和怀疑苏联科学技 術成就的人，人造地球衛星發射的成功，这个 “小小 的月亮”，不能不是一副清醒刘。

科学院和科联、科普最近召开了一次人造地球衛 星座談会, 到会的許多科学家發表了很好的意胃。特 别是有些科学家, 就其学科專業, 談了人造地球衡星 的發射成功对于今后有关学科的科学研究工作的傽大 影响和开辟新紀元的意义，使我們有更明确的認職和 更梁刻的体会。我現在想着重从这件事联系起來談一

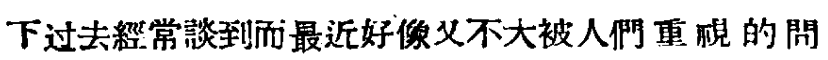
题，郎是在我們磨沅苏联十月革命四十祘年紀念的革 